\title{
The Impact of Health Insurance on Health-care Utilisation and Out-of-Pocket Payments in South Africa
}

\author{
John Ele-Ojo Ataguba a and Jane Goudge ${ }^{\mathrm{b}}$ \\ ${ }^{a}$ Health Economics Unit, School of Public Health and Family Medicine, University of Cape Town, \\ Anzio Road, Observatory, 7925, South Africa. \\ E-mail: john.ataguba@uct.ac.za \\ ${ }^{\mathrm{b}}$ Centre for Health Policy, School of Public Health, University of the Witwatersrand, Private Bag 3, \\ Wits 2050, South Africa. \\ E-mail: jane.goudge@gmail.com
}

Health insurance is an alternative to direct out-of-pocket (OOP) financing. It aims to improve access to care and reduce direct OOP payments. However, this may not be the case if there is high cost sharing and limited cover. This paper uses the methodology of propensity score matching to investigate the impact of private insurance via membership of a medical scheme in South Africa on health-care utilisation and OOP payments. The paper finds that insurance coverage increases the use of private health services as would be expected but there is no significant effect on the use of public services. Further, such coverage does not result in lower OOP payments for scheme members compared to nonmembers. This calls for a need to design health insurance, in South Africa, in the form that not only ensures adequate utilisation of health services but also provides financial protection to the insured as reflected in the current commitment for a National Health Insurance.

The Geneva Papers (2012) 37, 633-654. doi:10.1057/gpp.2012.35

Keywords: health insurance; impact evaluation; South Africa; health-care utilisation; out-of-pocket payments

Article submitted 28 January 2012; accepted 11 July 2012; published October 2012

\section{Introduction}

Access to health care is an important determinant in assessing equity in health-care delivery. ${ }^{1}$ In developing countries, health-care utilisation is influenced not only by demand constraints but also by supply constraints. In some instances, such utilisation is determined solely by the ability to pay rather than the need for care. ${ }^{2}$ This situation can impose heavy financial burdens on individuals as well as households and in certain instances can impoverish them or lead to financial catastrophe. ${ }^{3}$ Also, inequities in health service utilisation have been documented; those who need health-care services are not receiving what might be considered a fair share of the benefits. ${ }^{4}$ In this context,

\footnotetext{
${ }^{1}$ Wagstaff et al. (1991).

2 See Ahmed et al. (2007).

${ }^{3}$ Wagstaff and van Doorslaer (2003), Ataguba (2012).

${ }^{4}$ Castro-Leal et al. (1999), Gupta et al. (2001), Ataguba and McIntyre (2012b).
} 
health insurance is viewed as an alternative to improve access to health care and reduce the direct financial burden in using care. ${ }^{5}$ While this is what is often predicted by the theory of health insurance, health insurance does not always provide the expected financial protection ${ }^{6}$ for those who are "insured". This is often due to inter alia high co-payments and limited insurance cover that may also reduce utilisation.

In South Africa, private health insurance schemes (called medical schemes) exist. Membership is voluntary and is almost exclusively for formal sector workers and sometimes their dependants. Each scheme offers a number of alternative benefit options that includes the prescribed minimum benefits (PMBs) and a combination of other services. All schemes are required to cover the PMB package that includes some hospital-based interventions and certain chronic diseases. Scheme members' contributions are related to the benefit option selected as such contributions are the same for each member for that benefit option. However, a few "closed" schemes, whose membership is restricted to a specific company or industry, exist that differentiate contributions by benefit option and income level. ${ }^{7}$ Medical schemes provide cover to only those who enrol and mainly for services provided in the private sector. Scheme members may utilise public sector services, which are expected to be paid for by their schemes. However, this is rarely the case. ${ }^{7}$ Currently, there are over 100 medical schemes ${ }^{8}$ covering about 16 per cent of the population, primarily the richer segment of the population. ${ }^{9}$ These schemes have small, different population pools, resulting in a general lack of cross-subsidisation in the medical schemes environment. ${ }^{9}$ While there were moves towards developing a risk-equalisation mechanism across the current medical schemes, this has never been implemented. ${ }^{10}$ Over the years, member contributions to medical schemes in South Africa have been increasing and becoming unaffordable for members who still have to make substantial co-payments when using health services. ${ }^{11}$ In some cases, a low-cost benefit option that provides limited cover is selected. The co-payments and choice of low-cost options can create financial burdens for scheme members. Public sector services are however available for a larger segment of the population. Apart from primary care services that are fully subsidised, users are charged fees at other public hospitals that are generally graduated by income groups.

This paper therefore seeks to assess the impact of medical scheme membership on the utilisation of public and private out-patient health-care services in South Africa. It also assesses the extent to which membership of a medical scheme leads to a reduction or otherwise in out-of-pocket (OOP) payments for scheme members. In the light of these objectives, the paper contributes to the international debates on universal health coverage. This is also the first study within the South African context to evaluate the extent to which the purchase of private health insurance impacts health service utilisation and financial protection. The rest of the paper is structured as follows:

\footnotetext{
${ }^{5}$ Jowett et al. (2003), Sepehri et al. (2006).

${ }^{6}$ Lindelow and Wagstaff (2005), Ekman (2007a), Wagstaff et al. (2009).

${ }^{7}$ Ataguba and McIntyre (2012a).

${ }^{8}$ Council for Medical Schemes (2010).

${ }^{9}$ McIntyre et al. (2008).

${ }^{10}$ McIntyre and Doherty (2004), McIntyre et al. (2008).

11 Ataguba and Akazili (2010), McIntyre (2010).
} 
the next section provides a brief overview of the South African health system. The methodology, including the strategy for implementing the propensity score matching, is then presented. This is followed by the empirical results. Thereafter, the discussion section follows. The final section provides a brief conclusion.

\section{The South African health system}

Like many health systems in the world, the South African health system is tiered. It consists of both private and public sectors. The apartheid system, which existed pre democracy in 1994, in many ways, influenced the current South African health care system. During the apartheid era, the health-care system was highly fragmented along the lines of population grouping. Different population groups had their own health department and administration, ${ }^{12}$ with separate hospitals and other public health facilities for blacks and whites. ${ }^{13}$ Health policy was characterised by the objective of maintaining economic and political power, and a higher quality of life for the minority white population group. ${ }^{13}$ Health services for the black majority were heavily underfunded and rural areas were also neglected. ${ }^{14}$ The period of democratic transition leading to the formal adoption of the 1996 constitution brought the various health administrations into the current structure - one national and nine provincial health departments. ${ }^{15}$ In order to redress inequalities and inequity in access to health care created by the apartheid system, user fees were initially abolished at public health facilities for services provided to children less than six years of age, pregnant and lactating mothers. This initiative was further expanded to cover all public sector primary health-care services in $1996 .^{13}$ However, private health services are available for individuals who can afford to pay for them. They are largely used by those who purchase private health insurance cover.

Financing health care in South Africa has continued to be a major equity challenge. Currently, the total health-care expenditure is over 8 per cent of the country's GDP. However, over 50 per cent of both financial and human health-care resources are located in the private health sector alone. ${ }^{16}$ The public sector is underfunded relative to the population it serves; the private sector alone accounts for over 60 per cent of total health-care expenditure. In 2008, it was estimated that about 43 per cent of total health-care funds was accounted for by general government revenue. This was almost equal to that accounted for by private medical schemes alone. ${ }^{17}$ Although these schemes account for over 43 per cent of total health-care funds, they only cover less than 16 per cent of the population. ${ }^{7}$ Disparities between the two sectors continue to grow as expenditure by private medical schemes is increasing far more rapidly than in the public sector on a per capita basis. ${ }^{17}$

\footnotetext{
${ }^{12}$ Kale (1995), Coovadia et al. (2009).

${ }^{13}$ McIntyre et al. (2007).

${ }^{14}$ Kale (1995); McIntyre and Gilson (2002).

${ }^{15}$ McIntyre et al. (2007), Coovadia et al. (2009).

${ }^{16}$ Coovadia et al. (2009).

${ }^{17}$ McIntyre et al. (2012).
} 
636

Because private medical schemes account for a substantial portion of total healthcare expenditure, and also have a high level of health-care expenditure per scheme member, it is expected that these schemes should at least provide financial protection to the enrolled that comprise less than one-sixth of the South African population.

\section{Methodology}

\section{Data}

The data comes from a nationally representative household survey - the SACBIA survey. ${ }^{18}$ The purpose of this survey was specifically to obtain accurate data on health service utilisation and household OOP payments. Data collection took place between April and July 2008 in all nine South African provinces. Two-stage sampling was used. To ensure a nationally representative sample, enumeration areas (EAs) were stratified by province, type of settlement (farm, informal settlement, tribal settlement, small holding and urban settlement) and population group (black African, coloured, Indian and white). The first stage selected 960 EAs or the primary sampling units with a probability proportional to the size of the EA in each stratum. In the second stage, five households were interviewed within each EA. In each household, the respondent was the head or an adult member who is normally responsible for major household decisions. The total sample size was 4,800 households (approximately 22,000 individuals). In the survey, the medical scheme status of each household member was collected.

Data on health services utilisation was collected using a disaggregated classification of health providers (public and private) of outpatient and inpatient care. In this paper, only utilisation of outpatient services at formal providers is considered. This is because the use of private inpatient services is almost exclusively determined by insurance coverage, and data on the utilisation of informal service providers is unreliable. The utilisation data analysed in the study includes visits to public hospitals (district, regional, provincial tertiary, national central and specialised hospitals); public clinics and community health centres (CHCs); private hospitals; private general practitioners (GPs); private specialists; private dentists and private retail pharmacies. The recall period for outpatient visits is one month. Further, in the survey, respondents provided information on all outpatient visits within the recall period and not just services used for a specific illness episode. This is considered an improvement over previous surveys, where the focus was a specific episode of illness and associated utilisation.

To account for seasonal patterns in disease incidence as well as variations in the health-seeking patterns of households, ${ }^{19}$ the visits to various providers were annualised using seasonality indices, ${ }^{20}$ rather than annualising using the fixed multiplicative scalar

18 The SACBIA (South African Consortium for Benefit Incidence Analysis) survey was a collaborative initiative by the Health Economics Unit, University of Cape Town; Centre for Health Policy, University of the Witwatersrand; the National Department of Health; and the London School of Hygiene and Tropical Medicine. SACBIA was funded by the South African National Department of Health, the European Union and data was collected by the Community Agency for Social Enquiry.

19 Jolly (1988), Sauerborn et al. (1996), Briet (2002).

${ }^{20}$ McIntyre and Ataguba (2011). 
of 12. For visits to public facilities, the seasonality index was generated from the District Health Information System, which documents total visits to individual public sector facilities in each month. For most private services, the indices were generated from data on utilisation patterns in each month provided by the largest medical scheme administrators. Each index essentially compares utilisation of each type of service in the month(s) in which household survey data was collected, with the average monthly utilisation over a full year. ${ }^{20}$ The index was obtained as:

$$
S I_{j k}=\left(\sum_{i=1}^{12} U_{i k}\right) /\left(U_{j k}\right) \text { for each } k \text { and } U_{j k}>0
$$

where $S I_{j k}$ is the seasonal index for month $j$ (i.e. when the survey was conducted), $U_{i k}$ is the total visits to a specified facility $k$ in month $i$, and $U_{j k}$ is the total visits to facility $k$ in month $j$.

OOP health-care payments included all health service costs of both outpatient and inpatient care, such as medicines, consultations, treatments and medical procedures, paid to the provider including co-payments. They however excluded transportation costs and insurance premiums paid by individuals and employers. The costs associated with outpatient visits were similarly annualised but inpatient costs were recorded as annual figures. SACBIA survey only collected data on monthly expenditure. Annual consumption expenditure was subsequently generated using the consumption regression approach. ${ }^{21}$ This was done by linking similar and relevant variables in the SACBIA data set to a nationally representative data set - the 2005/2006 Income and Expenditure Survey (IES), which contains very detailed information on annual consumption expenditure. The aggregate annual consumption in the IES is regressed on a set of selected variables - frequent monthly expenditure and a set of significant household characteristics (such as rural/urban location, province of residence, population group, age of household head and household size) that were measured in the same way and common to both the SACBIA and the IES surveys. The total annual consumption expenditure was predicted in the SACBIA survey using the estimated coefficients from the previous regression as weights. ${ }^{21}$ The validity of the predicted consumption expenditure was confirmed by comparing with that reported in the IES and also its consistency was assessed across provinces and population groups. The annualised expenditure was robust when the densities and trends were compared across both data sets.

The complete data set is composed of 21,593 individuals. However, different subsets of the sample were created for each specific analysis. Only 5,163 individuals representing 24 per cent of the study population reported visiting at least one "formal" health-care facility within the recall period. The effective sample size for the impact evaluation was 2,434 individuals for the OOP payment analysis, representing those who paid OOP for care; 1,581 for utilisation of formal private outpatient facilities; 3,864 for the utilisation of formal public outpatient facilities; and 5,163 for

\footnotetext{
${ }^{21}$ See O'Donnell et al. (2008).
} 
the utilisation of any formal outpatient facilities. For each sub-analysis, about 14 per cent are scheme members (i.e. the treated group). This is a similar proportion of scheme members in South Africa. ${ }^{9}$ However, in the analysis of private outpatient utilisation, about 43 per cent are scheme members.

\section{The methodology of propensity score matching}

The "propensity score matching" approach is a method used to obtain unbiased estimates of the effect of a variable on an outcome of interest. It is used here to establish the difference between a participant's outcome before and after "treatment"22 (i.e. before and after becoming a scheme member). It is the case however that, in cross-sectional data sets, outcomes before and after treatment cannot be observed for the same individual. Information is only available for individuals who are either scheme members or not. Rosenbaum and Rubin ${ }^{23}$ propose the use of "balancing scores" $b(X)$ to match scheme and non-scheme members in such instances. Such balancing scores involve trying to match each medical scheme member with a non-member who has similar characteristics. The score is based on information on the relevant observable characteristics $X$ such that the conditional distribution of $X$, given $b(X)$, is independent of insurance status. ${ }^{24,25}$ Different methods may be used to generate the balancing scores. In this paper, the propensity score matching (PSM) or the probability of being a scheme member (given the observed covariates $X$ ) is used.

The treatment effect ${ }^{26}$ of interest is the average treatment effect on the treated $(A T T) .{ }^{27}$ This presupposes that there is a region of common support (i.e. there is a fair amount of overlap in the distribution of both the treated and the control units over the range of estimated propensity score) and the conditional independence assumption holds. In the context of this paper, and in South Africa, it is important to note that for the conditional independence assumption, the purchase of private insurance is based largely on observable characteristics. ${ }^{28}$ These are used in the construction of the propensity scores $p(X)$. However it is also possible that some unobservable factors,

${ }^{22}$ In the literature, two groups are distinguished - the treated and the untreated groups. The treated group may be referred to as a group of participants while the untreated group as the control group. In this paper, the treated group is referred to as "medical scheme members" or "scheme members" while the untreated are referred to as "non-scheme members". These terminologies are used interchangeably in the paper.

${ }^{23}$ Rosenbaum and Rubin (1983b).

${ }^{24}$ This is often referred to as the "conditional independence" assumption or the "selection on observables" assumption.

${ }^{25}$ Caliendo and Kopeinig (2008).

${ }^{26}$ This is in the language of treatment effect literature. This is analogous to the effect of scheme membership.

${ }^{27}$ This is one of the widely used parameters for impact assessment. It is used particularly when we are interested in the impact of insurance on those who are scheme members. This gives the extent of financial protection, for instance for those who are scheme members. In this case, the ATT is interpreted as how much OOP health-care payment (or visits to health-care facilities) on average a scheme member pays (or makes) over a non-scheme member. The choice of parameter to estimate depends on the specific evaluation context and the specific research question asked (Caliendo and Kopeinig, 2008).

${ }^{28}$ Borghi et al. (2009). 
such as ex ante health status and aversion to risk, play some role in the decision to insure.

The $A T T$ can be estimated as:

$$
\tau_{A T T}^{P S M}=E(\tau \mid d=1)=E\left(y_{1 i} \mid p(X), d_{i}=1\right)-E\left(y_{0 i} \mid p(X), d_{i}=0\right),
$$

where $d=1$ for a scheme member and $d=0$ for a non-scheme member; $y_{1 i}$ and $y_{0 i}$ represent the outcome (OOP payments or health-care utilisation) for a scheme and non-scheme member, respectively.

If there are no unobservable pre-treatment characteristics, the estimate obtained from Eq. (1) is interpreted as the unbiased $A T T$. From a policy perspective, this measure is explained as the average OOP payment (or health-care utilisation) for a typical scheme member over non-scheme member. The propensity score $p(X)$ is computed simply as the probability of being a scheme member, given the observable characteristics or variables $X .^{29}$

\section{Implementation strategy}

The propensity scores are estimated using a simple probit model. In choosing variables for inclusion, only those that affect both the enrolment decision and the potential outcome but are unaffected by insurance or treatment are included. ${ }^{30}$ In the case of a subsidised health insurance programme, Trujillo et al. ${ }^{31}$ note that the probability of participating for children under 16 years of age is influenced by the values of the head of the household. Therefore, the enrolment of children is determined by some relevant characteristics of the household head such as education level and employment status. In this paper, variables included in the probit model for $p(X)$ include education, employment status and the civil status of the household head; age, race, sex, location of the individual and the relationship between the head of the household and the individual (see Table 4 for all the variables used). Quintiles of per capita consumption expenditure are also included as a measure of socio-economic status of the individual. This was because enrolment is heavily concentrated among the richest South Africans. These were selected based on a review of the relevant literature on medical schemes in South Africa. It is important to note that we considered the inclusion of ex ante health status using an indicator of a chronic health condition. This variable was however not a statistically significant predictor of scheme membership.

In choosing which algorithm to use for propensity score matching, particularly in large samples, and when there is a considerable degree of overlap in propensity scores between the treatment and control groups, there is generally no "superior" estimator as these normally converge. ${ }^{32}$ In small samples, however, the choice of the algorithm is

\footnotetext{
${ }^{29}$ Rosenbaum and Rubin (1983a), Trujillo et al. (2005), Caliendo and Kopeinig (2008).

${ }^{30}$ While the variables for participants and non-participants should be observed from the same survey questionnaire (Heckman et al., 1999), a stronger criterion requires that the variables are not affected by anticipation of participation (Caliendo and Kopeinig, 2008).

31 Trujillo et al. (2005).

${ }^{32}$ See Dehejia and Wahba (2002) and Caliendo and Kopeinig (2008).
} 
640

important. ${ }^{33}$ In such a case, when choosing a matching algorithm it is important to compare the results obtained from using the different algorithms. If the results differ at least substantially, there is a need to investigate further the reason for the disparity. ${ }^{34}$ Following Dehejia and Wahba, ${ }^{35}$ all control units (i.e. non-scheme members) with an estimated propensity score lower than the lowest estimates of $p(X)$ for the treated units (i.e. scheme members) are dropped from the computation of the $A T T$. Further, to guarantee the common support condition, 10 per cent of the treatment at which the propensity score density of the control group is the lowest was dropped. ${ }^{36}$ This is to ensure that there is a sufficient pool of non-scheme members to select randomly from and match with scheme members.

In order to assess the sensitivity of our results to the choice of matching algorithm, as noted earlier, we implement five matching algorithms - one-to-one, kernel, radius, nearest neighbour (using five nearest neighbours with replacement), and local linear regression using a tolerance level (or calliper distance). ${ }^{37}$

One-to-one matching was used to match each scheme member randomly with a nonscheme member based on similarity in estimated propensity score. Nearest neighbour (NN) matching was used to match a scheme member with five randomly selected nonscheme members with estimated propensity score within a predetermined calliper distance. A disadvantage with the NN matching is the difficulty in specifying the appropriate tolerance level. When the NN matching is done with replacement, bias in the average treatment effect is reduced but variance in the estimation ${ }^{38}$ increases. $^{2}$ Bootstrap methodology can be used to obtain the standard errors in such cases. However, the validity of bootstrapping in such cases is questionable. ${ }^{39}$ The radius matching is similar to the NN matching, where all comparison members within the calliper distance are used rather than only five non-scheme members. Other algorithms such as the kernel and local linear matching ${ }^{40}$ use weighted (kernel weights) averages of nearly all individuals in the non-scheme group, within the region of common support, to construct the counterfactual for matching. The major challenges with the kernel and local linear matching, however, lie in the choice of appropriate kernel function and particularly bandwidth parameter. ${ }^{25}$ The smaller (higher) the value of bandwidth parameter, the lesser (higher) is the bias but higher (lower) is the variance in the estimation of the treatment effect. In this paper, we implement these algorithms using a default bandwidth (i.e. 0.06) and the Epanechnikov kernel function. ${ }^{36}$ All estimations were performed in Stata $11^{41}$ using the psmatch2 routine. ${ }^{36}$

\footnotetext{
${ }^{33}$ Heckman et al. (1997).

${ }^{34}$ See Caliendo and Kopeinig (2008) for a detailed discussion on this.

${ }^{35}$ Dehejia and Wahba (1999).

${ }^{36}$ Leuven and Sianesi (2003).

${ }^{37}$ This is a quarter of the standard deviation of the estimated propensity score as suggested by Rosenbaum and Rubin (1985, p. 37) and Cochran and Rubin (1973).

${ }^{38}$ See Caliendo and Kopeinig (2008) for some issues with the NN matching algorithm especially as it relates to the trade-off between bias and variance.

${ }^{39}$ Abadie and Imbens (2008).

${ }^{40}$ Heckman et al. (1997, 1998).

${ }^{41}$ StataCorp (2009).
} 


\section{Empirical results}

In Table 1, the summary statistics show that on average there are six members in a household. Only about 40 per cent of household heads are formally employed. There are more male-headed households (51 per cent), and about 40 per cent of the population reside in rural areas. The level of education among the household heads is relatively low. The racial distribution shows that the majority (over 80 per cent) of the population is black or African.

For outpatient health-care utilisation, there are differences across scheme membership status (Table 2). In clinics and $\mathrm{CHCs}$, there are on average 2.3 and 0.45 visits per capita per annum for non-scheme members and scheme members, respectively. In district hospitals, there are about 0.4 visits per person per year, with higher visits among non-scheme members. The same pattern occurs in regional and provincial tertiary hospitals. In national central hospitals, there are about 0.12 visits per capita per year, with higher visits among scheme members.

Unlike in public facilities, from Table 2, scheme members use more private facilities. While there are about 0.44 visits per person per year to a private GP, the figure for scheme members is over 1.5 visits. The same pattern holds for visits to private specialists, dentists and pharmacists (Table 2).

On average, for those who utilise health services, OOP costs for outpatient care at public facilities tend to be lower than those at private facilities both for scheme and non-scheme members (Table 3). This is due to exemptions and subsidised care. Nonscheme members use less of but spend more on average for health care in private facilities compared to scheme members. However, overall, scheme members spend more in absolute terms OOP than non-scheme members. This is because the majority of scheme (non-scheme) members use private (public) facilities.

In Table 4, we present the results of the probit estimation of the factors that predict enrolment. The factors in column B include an indicator of health status while column A excludes this variable. The health status variable in column B was not statistically significant $(p$-value $=0.9)$ and as such the estimates of column A were used to generate the propensity scores. ${ }^{42}$ Moreover, the coefficients in both columns A and B are identical. After controlling for several covariates, the significant factors that predict enrolment include the employment status of the head of the household, consumption expenditure quintiles, location, sex, civil status as well as the education level attained by the head of the household. Race, relationship with the head of the household and age also significantly predict enrolment.

An individual from a household with a formally employed head is more likely to be a scheme member compared with their counterparts. Wealthier households are more likely to enrol household members. This has also been confirmed elsewhere. ${ }^{43}$ In countries

\footnotetext{
${ }^{42}$ The quality of matching was assessed by comparing the means and proportions of relevant variables across matched and un-matched scheme and non-scheme members. Also, the region of common support was examined for all analyses. These results have not been presented here but are available from the authors upon request.

${ }^{43}$ Harmon and Nolan (2001), Höfter (2006), Chankova et al. (2008).
} 
Table 1 Variable description

\begin{tabular}{|c|c|c|c|c|c|}
\hline Variable & Description & $\begin{array}{l}\text { Mean or } \\
\text { proportion }\end{array}$ & Std. dev. & Min & Max \\
\hline HH size & Household size & 5.82 & 2.68 & 1 & 13 \\
\hline $\begin{array}{l}\text { Formally employed } \\
\text { HH head }\end{array}$ & $\begin{array}{l}\text { Dummy variable represented employed } \\
\text { or not employed (formally employed }=1 \text { ) }\end{array}$ & 0.44 & 0.50 & 0 & 1 \\
\hline Female-headed $\mathrm{HH}$ & Households headed by female & 0.49 & 0.50 & 0 & 1 \\
\hline Male & $\begin{array}{l}\text { Sex of household member where the main } \\
\text { category is male }\end{array}$ & 0.44 & 0.50 & 0 & 1 \\
\hline Rural & Whether household is located in the rural area & 0.40 & 0.49 & 0 & 1 \\
\hline Informal urban & $\begin{array}{l}\text { Whether household is located in an informal } \\
\text { urban area }\end{array}$ & 0.17 & 0.37 & 0 & 1 \\
\hline Formal urban & $\begin{array}{l}\text { Whether household is located in an informal } \\
\text { urban area }\end{array}$ & 0.43 & 0.50 & 0 & 1 \\
\hline $\begin{array}{l}\text { No Education } \\
\text { (head of } \mathrm{HH} \text { ) }\end{array}$ & $\begin{array}{l}\text { Whether the household head is formally } \\
\text { educated or not (no formal education }=1 \text { ) }\end{array}$ & 0.13 & 0.33 & 0 & 1 \\
\hline $\begin{array}{l}\text { Primary Education } \\
\text { (head of } \mathrm{HH})\end{array}$ & $\begin{array}{l}\text { Whether the household head had at most } \\
\text { primary education or not (primary } \\
\text { education }=1 \text { ) }\end{array}$ & 0.27 & 0.44 & 0 & 1 \\
\hline $\begin{array}{l}\text { Secondary Education } \\
\text { (head of } \mathrm{HH} \text { ) }\end{array}$ & $\begin{array}{l}\text { Whether the household head had at most } \\
\text { secondary education or not (secondary } \\
\text { education }=1 \text { ) }\end{array}$ & 0.50 & 0.50 & 0 & 1 \\
\hline $\begin{array}{l}\text { Tertiary Education } \\
\text { (head of } \mathrm{HH})\end{array}$ & $\begin{array}{l}\text { Whether the household head had tertiary } \\
\text { education or not (tertiary education }=1 \text { ) }\end{array}$ & 0.10 & 0.30 & 0 & 1 \\
\hline Health status & $\begin{array}{l}\text { Whether an individual has been taking } \\
\text { medicines regularly for the past six months or } \\
\text { more, which were prescribed } \\
\text { by a trained health professional. This } \\
\text { is used as an indicator of a chronic } \\
\text { health condition }\end{array}$ & 0.11 & 0.31 & 0 & 1 \\
\hline $\begin{array}{l}\text { Agecat } 1 \\
(0-5 \text { years })\end{array}$ & $\begin{array}{l}\text { Household member aged between } 0 \\
\text { and } 5 \text { years }\end{array}$ & 0.12 & 0.33 & 0 & 1 \\
\hline $\begin{array}{l}\text { Agecat } 2 \\
(6-19 \text { years })\end{array}$ & $\begin{array}{l}\text { Household member aged between } 6 \\
\text { and } 19 \text { years }\end{array}$ & 0.32 & 0.47 & 0 & 1 \\
\hline $\begin{array}{l}\text { Agecat } 3 \\
(20-40 \text { years })\end{array}$ & $\begin{array}{l}\text { Household member aged between } 20 \\
\text { and } 40 \text { years }\end{array}$ & 0.31 & 0.46 & 0 & 1 \\
\hline $\begin{array}{l}\text { Agecat } 4 \\
(41-60 \text { years) }\end{array}$ & $\begin{array}{l}\text { Household member aged between } 41 \\
\text { and } 60 \text { years }\end{array}$ & 0.17 & 0.38 & 0 & 1 \\
\hline $\begin{array}{l}\text { Agecat } 5 \\
\text { ( } 61 \text { years or above) }\end{array}$ & Household member aged 60 years or older & 0.07 & 0.26 & 0 & 1 \\
\hline White & Race dummy $($ whites $=1 ;$ non-whites $=0$ ) & 0.07 & 0.25 & 0 & 1 \\
\hline Black/African & $\begin{array}{l}\text { Race dummy }(\text { black } / \text { African }=1 \\
\text { non-black } / \text { African }=0)\end{array}$ & 0.82 & 0.39 & 0 & 1 \\
\hline Asian/Indian & $\begin{array}{l}\text { Race dummy }(\text { Asian } / \text { Indian }=1 \\
\text { non-Asian } / \text { Indian }=0)\end{array}$ & 0.02 & 0.15 & 0 & 1 \\
\hline Coloured & $\begin{array}{l}\text { Race dummy }(\text { coloured }=1 \\
\text { non-coloured }=0 \text { ) }\end{array}$ & 0.09 & 0.29 & 0 & 1 \\
\hline
\end{tabular}


Table 2 Average utilisation rates (number of visits per person per annum) for different providers

\begin{tabular}{|c|c|c|c|c|c|c|c|c|c|c|}
\hline & \multicolumn{5}{|c|}{ Public facilities } & \multicolumn{5}{|c|}{ Private facilities } \\
\hline & $\begin{array}{l}\text { Clinics/ } \\
\text { CHCs }\end{array}$ & $\begin{array}{l}\text { District } \\
\text { hospital }\end{array}$ & $\begin{array}{c}\text { Regional } \\
\text { hospital }\end{array}$ & $\begin{array}{c}\text { Provincial } \\
\text { tertiary } \\
\text { hospital }\end{array}$ & $\begin{array}{c}\text { National } \\
\text { central hospital }\end{array}$ & $\begin{array}{c}\text { Private } \\
G P\end{array}$ & $\begin{array}{c}\text { Private } \\
\text { specialist }\end{array}$ & $\begin{array}{l}\text { Private } \\
\text { hospital }\end{array}$ & $\begin{array}{l}\text { Private } \\
\text { dentist }\end{array}$ & $\begin{array}{c}\text { Private } \\
\text { pharmacist }\end{array}$ \\
\hline National & 2.094 & 0.383 & 0.276 & 0.067 & 0.117 & 0.443 & 0.134 & 0.194 & 0.105 & 0.259 \\
\hline \multicolumn{11}{|c|}{ Scheme membership status } \\
\hline Members & 0.451 & 0.101 & 0.057 & 0.041 & 0.155 & 1.590 & 0.448 & 0.994 & 0.554 & 0.942 \\
\hline Non-members & 2.303 & 0.419 & 0.304 & 0.071 & 0.113 & 0.291 & 0.093 & 0.088 & 0.045 & 0.168 \\
\hline
\end{tabular}

Source: Authors' calculations based on SACBIA 2008 data set.

Note: In annualising the visits, they have been adjusted for seasonal variations in utilisation.

Table 3 Average out-of-pocket payments per person per annum for outpatient care by provider (2008 ZAR)

\begin{tabular}{lccccccr}
\hline & $\begin{array}{c}\text { Public } \\
\text { hospital }\end{array}$ & $\begin{array}{c}\text { Private } \\
\text { GP }\end{array}$ & $\begin{array}{c}\text { Private } \\
\text { specialist }\end{array}$ & $\begin{array}{c}\text { Private } \\
\text { hospital }\end{array}$ & $\begin{array}{c}\text { Private } \\
\text { dentist }\end{array}$ & $\begin{array}{c}\text { Private } \\
\text { pharmacy }\end{array}$ & Total \\
\hline National & 193.61 & $1,285.05$ & $2,937.94$ & $4,620.98$ & $1,304.47$ & $1,045.57$ & 695.57 \\
\multicolumn{2}{l}{$\begin{array}{l}\text { Scheme membership status } \\
\text { Members }\end{array}$} & & & & & & \\
Non-members & 183.58 & $1,798.70$ & $3,956.98$ & $8,291.68$ & $1,699.06$ & $1,018.92$ & 574.10 \\
\hline
\end{tabular}

Source: Authors' calculations based on SACBIA 2008 data set.

Note: In 2008, \$1 = R8.

where compulsory national insurance schemes exist, such as Australia and the U.K., evidence shows that employment status does not affect individuals' entitlements to medical care. ${ }^{44}$

Better educated household heads are more likely to enrol members than those without any formal education as was also reported elsewhere. ${ }^{45}$ The result is significant for household heads with at least some level of secondary education. Interestingly, within households, younger members (less than 21 years of age), including those under five, are more likely to be scheme members compared to those aged between 21 and 40 years. In turn, household members aged between 41 and 60 years are more likely to be scheme members than those between 21 and 40 years. This is in keeping with the hypothesis that medical needs increase with age. ${ }^{44}$ While all these differences are statistically significant, members who are aged 60 years or above are more likely to be scheme members than their younger counterparts of 21-40 years, but this is not statistically significant. A member of the white race group compared

\footnotetext{
${ }^{44}$ Höfter (2006).

${ }^{45}$ Harmon and Nolan (2001), Höfter (2006).
} 
Table 4 Probit regression - predictors of medical scheme membership

Dependent variable $==>$ scheme member $(=1) /$ non-scheme member $(=0)$

(A)

(B)

Household head characteristics

Formally employed head

Primary Education (head of $\mathrm{HH})^{\mathrm{a}}$

Secondary Education (head of $\mathrm{HH})^{\mathrm{a}}$

Tertiary Education (head of $\mathrm{HH})^{\mathrm{a}}$

Married household head ${ }^{\mathrm{b}}$

Widow/widower household head ${ }^{\mathrm{b}}$

Divorced household head ${ }^{\mathrm{b}}$

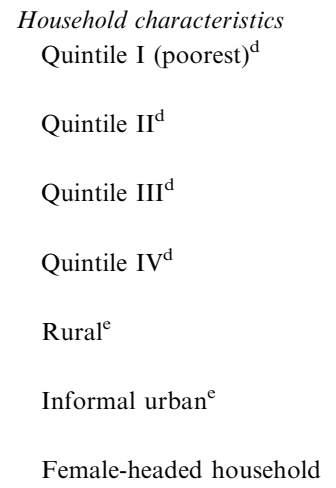

$-1.2292^{* * * *}$

$\begin{array}{lc}0.3907 * * * & 0.3904^{* * *} \\ (0.0544) & (0.0546) \\ 0.0165 & 0.0165 \\ (0.1253) & (0.1253) \\ 0.3467 * * * & 0.3466^{* * *} \\ (0.1192) & (0.1191) \\ 1.1176^{* * * *} & 1.1175^{* * *} \\ (0.1336) & (0.1335) \\ 0.2284 * * * & 0.2282^{* * *} \\ (0.0685) & (0.0685) \\ 0.2045^{* *} & 0.2045 * * \\ (0.0933) & (0.0933) \\ 0.0770 & 0.0770 \\ (0.1217) & (0.1217)\end{array}$

$-1.2293 * * *$

(0.1225)

$-1.0865^{* * *}$

$(0.1021)$

$-0.6851 * * *$

(0.0815)

$-0.5075^{* * *}$

(0.0658)

$-0.3095 * * *$

$(0.0721)$

$-0.4425 * * *$

(0.0762)

$-0.1044 *$

(0.0631)

\section{Individual characteristics}

Male

$$
\begin{gathered}
0.0169 \\
(0.0259) \\
0.2409^{* * *} \\
(0.0551) \\
0.1562^{* * *} \\
(0.0455) \\
0.1895^{* * *} \\
(0.0485) \\
0.0451 \\
(0.0675) \\
0.4827^{* * *} \\
(0.0801) \\
-0.0971 * * \\
(0.0459) \\
-0.2856^{* * *} \\
(0.0622)
\end{gathered}
$$$$
0.0166
$$ 
Table 4 (continued)

\begin{tabular}{lcc} 
Dependent variable $=>$ scheme member $(=1)$ /non-scheme member $(=0)$ & $(B)$ \\
\hline & $(A)$ & $-0.5821^{* *}$ \\
\hline Relationship with the head (non-relatives) ${ }^{\mathrm{c}}$ & $-0.5819^{* *}$ & $(0.2375)$ \\
Health status & $(0.2375)$ & -0.0070 \\
& & $(0.0511)$ \\
Constant & $-1.3036^{* * *}$ & $-1.3024^{* * *}$ \\
& $(0.1372)$ & $(0.1377)$ \\
Pseudo $R^{2}$ & 0.337 & 0.337 \\
Number of observations & 20,724 & 20,724 \\
Wald $\chi^{2}$ & $1,230.72^{* * *}$ & $1,238.20^{* * *}$ \\
Pseudolikelihood & $-4,868.33$ & $-4,868.32$ \\
\hline
\end{tabular}

${ }^{a}$ No schooling (head of $\mathrm{HH}$ ).

${ }^{\mathrm{b}}$ Single household head.

${ }^{\mathrm{c}}$ Relationship with the head (Head).

${ }^{\mathrm{d}}$ Quintile V (richest).

${ }^{\mathrm{e}}$ Formal urban.

${ }^{\mathrm{f}}$ Agecat3 (21-40 years).

Note: Robust standard errors reported in parenthesis allow for intragroup correlation.

$* * *, * *$ and $*$ statistically significant difference at 1 per cent, 5 per cent and 10 per cent levels, respectively.

with other race groups is more likely to be a scheme member. This may be for historical reasons as membership was initially restricted to the white population.

The relationship of the household members to the head determines who becomes a scheme member and who does not. Children as well as other relatives and nonrelatives are less likely to be scheme members compared with the head of the household. More importantly, non-relatives are least likely to be scheme members. Children are the most likely to be scheme members compared with other relatives. Also, individuals from households with a married or widowed head are more likely to be scheme members compared with those from a single-headed household. This conforms to the findings in Chile and Ireland. ${ }^{45}$ While individuals from households headed by a divorced person are more likely than in a single-headed household to be scheme members, this is not statistically significant. As can also be observed, individuals from male-headed households are more likely to be scheme members than from femaleheaded households. This is in contrast to that reported in West Africa by Chankova et al. ${ }^{46}$ where community-based health insurance schemes exist. Males are more likely to be scheme members than females, though the result is not statistically significant.

In Table 5, the estimates of the impact of insurance on the utilisation of health services and OOP payments in South Africa are presented. The results in column 4 show that, on average, a comparable scheme member spends between R818 and $\mathrm{R} 1,190$ (in 2008 prices) per annum more than a non-scheme member on OOP expenses

${ }^{46}$ Chankova et al. (2008). 
Table 5 Estimates of the impact of health insurance on health-care utilisation and out-of-pocket (OOP) payments in South Africa

\begin{tabular}{|c|c|c|c|c|}
\hline \multirow[t]{3}{*}{ Matching algorithm } & \multicolumn{4}{|c|}{$\begin{array}{c}\text { Average treatment effect on treated (ATT) } \\
(2008 \text { Rand }) / \text { visits per person per year }\end{array}$} \\
\hline & \multicolumn{3}{|c|}{ Visits per capita per annum } & \multirow{2}{*}{$\begin{array}{c}\text { OOP payments } \\
\text { per person per year } \\
\text { (4) }\end{array}$} \\
\hline & $\begin{array}{l}\text { Private facility } \\
\text { (1) }\end{array}$ & $\begin{array}{l}\text { Public facility } \\
\text { (2) }\end{array}$ & $\begin{array}{l}\text { Any facility } \\
\text { (3) }\end{array}$ & \\
\hline One-to-one matching & $\begin{array}{r}1.860^{*} \\
(1.048) \\
{[398]}\end{array}$ & $\begin{array}{l}2.598 \\
(1.792) \\
{[117]}\end{array}$ & $\begin{array}{c}1.142 \\
(1.110) \\
{[579]}\end{array}$ & $\begin{array}{c}935.04 * * \\
(390.090) \\
{[287]}\end{array}$ \\
\hline Kernel matching & $\begin{array}{c}1.797 * * \\
(0.867) \\
{[623]}\end{array}$ & $\begin{array}{c}-0.014 \\
(1.808) \\
{[117]}\end{array}$ & $\begin{array}{c}0.696 \\
(0.927) \\
{[709]}\end{array}$ & $\begin{array}{c}961.56 * * \\
(379.791) \\
{[312]}\end{array}$ \\
\hline Radius matching & $\begin{array}{c}1.925 * * \\
(0.912) \\
{[623]}\end{array}$ & $\begin{array}{c}0.039 \\
(1.826) \\
{[117]}\end{array}$ & $\begin{array}{c}0.692 \\
(0.971) \\
{[709]}\end{array}$ & $\begin{array}{c}865.37 * * \\
(400.14) \\
{[312]}\end{array}$ \\
\hline Nearest neighbour matching & $\begin{array}{c}2.064 * * \\
(0.973) \\
{[623]}\end{array}$ & $\begin{array}{l}0.872 \\
(1.954) \\
{[117]}\end{array}$ & $\begin{array}{c}0.762 \\
(1.178) \\
{[709]}\end{array}$ & $\begin{array}{c}1,190.60 * * * \\
(379.468) \\
{[312]}\end{array}$ \\
\hline Local linear regression matching & $\begin{array}{c}1.802 * * \\
(0.891) \\
{[623]}\end{array}$ & $\begin{array}{c}-0.032 \\
(1.822) \\
{[117]}\end{array}$ & $\begin{array}{c}0.568 \\
(0.962) \\
{[709]}\end{array}$ & $\begin{array}{c}817.63^{* *} \\
(391.257) \\
{[312]}\end{array}$ \\
\hline Number of observations (non-scheme members) & 897 & 3,699 & 4,352 & 2,088 \\
\hline
\end{tabular}

Standard errors reported in parentheses; number of observations (scheme members) in square brackets. Source: Authors' calculations.

Note: In 2008, \$1 = R8.

$* * *, * *$ and $*$ statistically significant at 1 per cent, 5 per cent and 10 per cent levels, respectively.

for health services. This difference is statistically significant. Columns 1-3 show the impact of insurance on the use of formal private, public or both public and private facilities. The results show that there is little difference (and not statistically significant) in the use of health services by scheme members over non-scheme members, especially for public facilities (column 2) but also for health services generally (column 3). The case of private facilities in column 1 stands out. Scheme members use more private facilities compared with non-scheme members and this is statistically significant for all of the matching algorithms. On average, a scheme member has approximately two private facility visits per annum more than the comparable non-scheme member.

\section{Discussion}

According to Harmon and Nolan, ${ }^{47}$ "the nature of demand for private health insurance itself depends on the institutional context in which that insurance operates". In the case of South Africa, private health insurance is voluntary and the majority of

\footnotetext{
${ }^{47}$ Harmon and Nolan (2001, p. 135).
} 
principal enrollees are those with formal sector employment. It is often a condition of employment. $^{28}$ However, whatever the nature of the health insurance system, economic theory postulates that health insurance will increase health-care utilisation, due to lower costs (or price) of utilising care. It is also expected to lower OOP costs or provide financial protection to the insured. ${ }^{48}$

Using the propensity score-matching technique for impact estimation, this paper shows that membership of medical schemes in South Africa does result in significant increases in private health-care visits but it has no significant impact on public visits or combined public and private facilities visit. This is not surprising because the use of private services is associated with membership of a private insurance scheme that covers mainly private care. ${ }^{49}$ The findings here confirm existing evidence that insurance increases utilisation. Greater use of private services by medical scheme members is not surprising as membership of a scheme explicitly entitles one to use private sector services. Medical scheme members seldom use public health services, ${ }^{50}$ which may be attributed to perceptions of quality of care/services differentials between public and private facilities but also to the fact that schemes focus on private providers in their preferred provider lists. For those who are not medical scheme members, the cost of private sector services is largely unaffordable.

Other studies that show positive impacts of health insurance on health-care demand and utilisation include those in Argentina ${ }^{51}$; in the Philippines for the ORT Health Plus Scheme ${ }^{52}$; in Burkina Faso for a community-based insurance scheme ${ }^{53}$; in Egypt for the School Health Insurance Programme (SHIP) ${ }^{54}$; in the Vietnamese Health Insurance $(\mathrm{VHI})^{55}$; in the voluntary health insurance in Vietnam ${ }^{56}$; in the subsidised health insurance programme (SUBS) in Columbia ${ }^{31}$; in Jordan ${ }^{57}$; and in Chile where there was an increase in utilisation for both private and publicly insured in terms of outpatient services though the result is negligible for hospitalisation. ${ }^{58}$ Also, in Ecuador, the Seguro Campesino Social, which targets the farming population, was shown to increase utilisation even though the impact was not statistically significant. ${ }^{59}$ Other studies have found a rather negligible impact of insurance on utilisation, such as Wagstaff ${ }^{60}$ for the Vietnamese health care fund for the poor (HCFP); or a rather mixed impact for the formal sector General Health Insurance (GHI) programme in Ecuador. ${ }^{59}$ While the GHI increased the use of curative care, there was no significant effect on the use of preventive care. Such mixed impacts were also observed in the

\footnotetext{
${ }^{48}$ Lindelow and Wagstaff (2005), Höfter (2006), Wagstaff et al. (2009).

${ }^{49}$ Borghi et al. (2009), Ataguba and Akazili (2010).

${ }^{50}$ Ataguba and McIntyre (2012b).

51 Bertranou (1998).

${ }^{52}$ Harmon and Nolan (2001).

53 Gnawali et al. (2009).

${ }^{54}$ Yip and Berman (2001).

${ }^{55}$ Wagstaff and Pradhan (2005), Wagstaff et al. (2009).

${ }^{56}$ Nguyen (2012).

${ }^{57}$ Ekman (2007b).

${ }^{58}$ Sapelli and Vial (2003), Höfter (2006).

${ }^{59}$ Waters (1999).

${ }^{60}$ Wagstaff (2010).
} 
results in this paper, which show that insurance may have differential impacts on health-care utilisation depending on the context. In the context of South Africa, the use of private outpatient services is responsive to being a scheme member. Though the direct comparison of the magnitudes of the impact may be difficult to make because the studies are based on different health systems and used different methodologies to arrive at the impact estimates, the overall picture is still of great policy importance.

Contrary to theory, the impact of insurance on OOP payments shows that OOP payments tend to be higher for scheme members compared with non-scheme members. Generally, as Castano et al. note, ${ }^{61}$ insurance systems are essentially aimed at "the spreading of risks among large population groups, which leads to the reduction of outof-pocket (OOP) payments which a household faces". While this has been confirmed in several studies, ${ }^{62}$ others have found rather conflicting evidence. ${ }^{63}$ Yip and Berman ${ }^{54}$ in Egypt report a reduction in OOP payments due to the SHIP; Jowett et al. ${ }^{64}$ show a reduction in OOP payments for Vietnam's not-for-profit health insurance scheme; and Wagstaff $^{60}$ also reports a reduction in OOP payments due to insurance in the government-funded HCFP. Ekman ${ }^{57}$ in Jordan also found a reduction in OOP due to insurance; and the risk of financial and catastrophic risks are reduced in Mexico from enrolment in the Seguro Popular scheme. ${ }^{65}$

While a reduction in OOP costs is expected, Lindelow and Wagstaff ${ }^{66}$ have also argued that the presence of insurance could induce providers of care to exploit informational asymmetry to their advantage. In practice, under such a scenario and where the insured have limited insurance cover, insurance may therefore not immediately result in a reduction in OOP payments. Also, insurers may impose copayments. ${ }^{67}$ This situation has arisen in several contexts such as in Zambia, where Ekman $^{68}$ shows that insurance does not guarantee adequate financial protection and in fact increases the risks of catastrophic spending. Also, in China, Lindelow and Wagstaff ${ }^{66}$ found that health insurance offers very limited financial protection. The VHI in Vietnam also does not always result in a reduction in OOP payments for the insured ${ }^{69}$ as the insured spend more OOP to use health-care services than the uninsured. The results showing negative impacts of insurance on OOP payments, as were found in the current study, risk destroying the very essence of insurance.

In South Africa, it is estimated that about two-thirds of total OOP expenditures are made by medical scheme members to private providers, in the form of co-payments, payments for services not covered by the scheme or payments when service benefits

${ }^{61}$ Castano et al. (2002, p. 5).

${ }^{62}$ Yip and Berman (2001), Jowett et al. (2003), Ekman (2007b), Wagstaff (2010).

${ }^{63}$ Lindelow and Wagstaff (2005), Ekman (2007a), Chankova et al. (2008), Wagstaff et al. (2009).

${ }^{64}$ Jowett et al. (2003).

${ }^{65}$ Gakidou et al. (2006).

${ }^{66}$ Lindelow and Wagstaff (2005).

${ }^{67}$ McIntyre et al. (2009).

${ }^{68}$ Ekman (2007a).

${ }^{69}$ Wagstaff et al. (2009). 
have been exceeded. ${ }^{70}$ It is not surprising, therefore, that these expenditures are higher among scheme members. Because of the rapidly escalating contributions to medical schemes, households that purchase medical scheme cover attempt to cushion the effect by, for instance, choosing low-cost options that entitle them to fewer services. Others choose to purchase cover for hospitalisation alone and pay OOP for outpatient services.

The results for South Africa need to be placed in context to fully understand the extent to which higher OOP payments for scheme members are not encouraging. Because the share of private health insurance in total health-care financing is large, it is expected that this will translate into reduced financial burden for medical scheme members. There are a number of factors that contribute to the high OOP payments by medical scheme members in South Africa. Of particular importance is the rapid increase in spending by schemes and hence in contribution rates. This is partly attributable to the system of payment of service providers on a fee-for-service basis by a third-party payer. ${ }^{17}$ In an effort to control the expenditure spiral, schemes have over time placed more and more limits on benefit packages (outside of the regulated PMB package) and increased co-payments. In addition, providers have been increasing their fees more rapidly than scheme reimbursement rates, leading to considerable balance billing. ${ }^{17}$ At the same time, many medical scheme members have been "buying down" to cheaper benefit options due to difficulties in affording the escalating scheme contributions. These factors have all contributed to a considerable and increasing burden of OOP payments on scheme members.

This inability of medical schemes to guarantee reduced OOP costs for enrolled members, despite the large share of total health-care financing accounted for by medical scheme contributions, suggests there is a need for reform of health-care financing in South Africa in line with the principle of equity in health care financing and increased financial protection. South Africa is currently in the process of introducing a tax-funded National Health Insurance system. ${ }^{71}$ Internationally, there is a call for countries to reform their health systems to achieve universal coverage. ${ }^{72}$ This call has arisen inter alia as a result of the inadequacy of various fragmented insurance schemes in countries to provide financial protection to citizens and the general absence of pre-payment mechanisms for funding health care. It should be the case that purchasing health insurance cover will grant the insured access to health services at lower direct costs. Studies have shown that countries with mandatory social or national health insurance and/or substantive tax funding tend to have reduced prevalence of OOP health-care expenditures compared with those that cover a limited segment of the population through pre-payment funding. ${ }^{73}$ This is because it eliminates fragmentation of schemes, and increases income and risk cross-subsidisation through an improved pool of funds. Going down this route, for South Africa, and

\footnotetext{
${ }^{70}$ McIntyre (2010).

${ }^{71}$ Department of Health (2011).

${ }^{72}$ Mills (2007), World Health Organization (2010).

${ }^{73}$ See Knaul et al. (2006) and Limwattananon et al. (2007).
} 
paying particular attention to the design of such a system, will likely lead to reductions in OOP payments and other associated challenges currently faced by medical schemes.

On a general note, it could be the case that differences in utilisation observed between scheme members and non-scheme members are due to moral hazard or adverse selection. Increased utilisation associated with a reduction in the direct cost of medical care may signal the presence of moral hazard. However, the results from this study show the inadequacy of private health insurance to cover the expected health-care costs of scheme members. Therefore, the effective direct cost of seeking care is higher for scheme members than anticipated. In this instance, moral hazard will be less pronounced. Also, adverse selection that occurs as a result of individuals being better informed about their risk type than insurers ${ }^{74}$ is unlikely to be driving the results. This is because the poor, in South Africa, that are burdened by major diseases, including non-communicable diseases, ${ }^{75}$ are largely non-scheme members. Also, membership of private insurance schemes is largely associated with formal sector employment. The negative (though not statistically significant) coefficient on health status in Table 4 (column B) also confirms the less likelihood of adverse selection.

One may also argue that the results in relation to OOP payments could be because we compare scheme members with non-scheme members who generally use subsidised public facilities. However, apart from fully subsidised primary-level services, user fees exist at public hospitals in South Africa. Although these fees are graduated according to a few broad income groups, they are considerable for middle- and higher-income patients, not all of whom are members of schemes and hence who have to cover these fees on an OOP basis. Non-scheme members who use private facilities also pay OOP for care.

This study has some limitations. Medical scheme membership in South Africa is not "homogeneous". There are many different schemes with different benefit options. These differences could not be accounted for in the analysis. However, it is important to note that all schemes cover the PMB package. Another limitation is that only observable characteristics are used in computing the propensity scores. It may not always be the case that the decision to insure is based only on observable characteristics. Some unobservable characteristics, such as risk aversion, may influence that decision. However, this variable was not included in our propensity score estimation due to lack of data. Also, endogeneity of insurance and utilisation may be plausible and were not accounted for in this paper. However, studies attempting to control for this, using the instrumental variable approach for instance to complement the matching methodology, have produced similar results, though the magnitude of the impacts differs. ${ }^{76}$ In the light of these, future studies on the impact of health insurance on health-care utilisation in South Africa may want to address this concern, and where possible draw on panel data sets and other methodologies.

\footnotetext{
${ }^{74}$ Zweifel et al. (2009).

${ }^{75}$ Ataguba et al. (2011).

${ }^{76}$ See Trujillo et al. (2005) for instance.
} 


\section{Conclusion}

The paper investigates the extent to which membership of a medical scheme in South Africa increases health-care utilisation and also reduces OOP payments. The findings show that while medical scheme membership increases the use of private health services, it does not result in lower OOP payments for members compared with nonscheme members. Also, scheme membership has no significant effect on the use of public health services. Though the increase in private health-care utilisation is expected, higher OOP payments are counter to predictions of economic theory. The significant differences in OOP payments between members and non-scheme members therefore indicate the need for reform of health financing in South Africa to improve access to affordable care and reduce financial burdens for households utilising health services.

\section{Acknowledgements}

This research was funded by the European Commission (Sixth Framework Programme; Specific Targeted Research Project no: 32289) and the IDRC (Grant number 103457). We also acknowledge the comments and suggestions made by Gavin Mooney, Di McIntyre and two anonymous reviewers. We further acknowledge the inputs of other members of staff at the Health Economics Unit, University of Cape Town where an earlier version was presented. The views expressed here are those of the authors and do not represent those of the funding agencies. The usual disclaimers apply.

\section{References}

Abadie, A. and Imbens, G.W. (2008) 'Notes and comments on the failure of the bootstrap for matching estimators', Econometrica 76(6): 1537-1557.

Ahmed, A.U., Hill, R.V., Smith, L.C., Wiesmann, D.M. and Frankenberger, T. (2007) The World's Most Deprived: Characteristics and Causes of Extreme Poverty and Hunger, Washington, D.C: International Food Policy Research Institute (IFPRI).

Ataguba, J.E. (2012) 'Reassessing catastrophic health care payments with a Nigerian case study', Health Economics, Policy and Law 7(3): 309-326.

Ataguba, J.E. and Akazili, J. (2010) 'Health care financing in South Africa: Moving towards universal coverage', Continuing Medical Education 28(2): 74-78.

Ataguba, J.E. and McIntyre, D. (2012a) 'Paying for and receiving benefits from health services in South Africa: Is the health system equitable?', Health Policy and Planning 27(Suppl 1): i35-i45.

Ataguba, J.E. and McIntyre, D. (2012b) 'Who benefits from health services in South Africa?' Health Economics, Policy and Law, advance online publication 2 April, DOI:10.1017/S1744133112000060.

Ataguba, J.E., Akazili, J. and McIntyre, D. (2011) 'Socioeconomic-related health inequality in South Africa: Evidence from general household surveys', International Journal for Equity in Health 10(48): 1-10.

Bertranou, F.M. (1998) 'Health care services utilisation and health insurance coverage', Revista de análisis económico 13(2): 25-30.

Borghi, J., Ataguba, J., Mtei, G., Akazili, J., Meheus, F., Rehnberg, C. and McIntyre, D. (2009) 'Methodological challenges in evaluating health care financing equity in data-poor contexts: Lessons from Ghana, South Africa and Tanzania', in D. Chernichovsky and K. Hanson (eds.) Innovations in Health System Finance in Developing and Transitional Economies, (Advances in Health Economics and Health Services Research, Volume 21), Bingley, U.K: Emerald Group Publishing.

Briet, O.J.T. (2002) 'A simple method for calculating mosquito mortality rates, correcting for seasonal variations in recruitment', Medical and Veterinary Entomology 16(1): 22-27.

Caliendo, M. and Kopeinig, S. (2008) 'Some practical guidance for the implementation of propensity score matching', Journal of Economic Surveys 22(1): 31-72. 
652

Castano, R.A., Arbelaez, J.J., Giedion, U.B. and Morales, L.G. (2002) 'Equitable financing, out-ofpocket payments and the role of health care reform in Colombia', Health Policy and Planning 17(Supplement 1): 5-11.

Castro-Leal, F., Dayton, J., Demery, L. and Mehra, K. (1999) 'Public spending on health care in Africa: Do the poor benefit?' The World Bank Research Observer 14(1): 49-72.

Chankova, S., Sulzbach, S. and Diop, F. (2008) 'Impact of mutual health organizations: Evidence from West Africa', Health Policy and Planning 23(4): 264-276.

Cochran, W.G. and Rubin, D.B. (1973) 'Controlling bias in observational studies: A review', Sankhya-The Indian Journal of Statistics Series A 35(4): 417-446.

Coovadia, H., Jewkes, R., Barron, P., Sanders, D. and McIntyre, D. (2009) 'The health and health system of South Africa: Historical roots of current public health challenges', The Lancet 374(9692): 817-834.

Council for Medical Schemes (2010) Council for Medical Schemes Annual Report 2009-2010, Pretoria: Council for Medical Schemes.

Dehejia, R.H. and Wahba, S. (1999) 'Causal effects in nonexperimental studies: Reevaluating the evaluation of training programs', Journal of the American Statistical Association 94(448): 1053-1062.

Dehejia, R.H. and Wahba, S. (2002) 'Propensity score-matching methods for nonexperimental causal studies', Review of Economics and statistics 84(1): 151-161.

Department of Health (2011) National Health Insurance in South Africa, Pretoria: National Department of Health, Republic of South Africa.

Ekman, B. (2007a) 'Catastrophic health payments and health insurance: Some counterintuitive evidence from one low-income country', Health Policy 83(2-3): 304-313.

Ekman, B. (2007b) 'The impact of health insurance on outpatient utilization and expenditure: Evidence from one middle-income country using national household survey data', Health Research Policy and Systems 5(1): $1-15$.

Gakidou, E., Lozano, R., Gonzalez-Pier, E., Abbott-Klafter, J., Barofsky, J. and Bryson-Cahn, C. (2006) 'Assessing the effect of the 2001-2006 Mexican Health Reform: An interim report card', The Lancet 368(9550): 1920-1935.

Gnawali, D., Pokhrel, S., Sié, A., Sanon, M., De Allegri, M., Souares, A., Dong, H. and Sauerborn, R. (2009) 'The effect of community-based health insurance on the utilization of modern health care services: Evidence from Burkina Faso', Health Policy 90(2-3): 214-222.

Gupta, S., Verhoeven, M. and Tiongson, E. (2001) Public spending on health care and the poor, International Monetary Fund Working Paper WP/01/127.

Harmon, C. and Nolan, B. (2001) 'Health insurance and health services utilization in Ireland', Health Economics 10(2): 135-145.

Heckman, J., Ichimura, H. and Todd, P. (1997) 'Matching as an econometric evaluation estimator: Evidence from evaluating a job training programme', Review of Economic Studies 64(4): 605-654.

Heckman, J.J., Ichimura, H. and Todd, P. (1998) 'Matching as an econometric evaluation estimator', Review of Economic studies 65(2): 261-294.

Heckman, J.J., LaLonde, R.J. and Smith, J.A. (1999) 'The economics and econometrics of active labor market programs', in O. Ashenfelter and D. Card (eds.) Handbook of Labor Economics, Amsterdam: Elsevier.

Höfter, R.H. (2006) 'Private health insurance and utilization of health services in Chile', Applied Economics 38(4): 423-439.

Jolly, R. (1988) 'A UNICEF perspective on the effects of economic crises and what can be done', in D.E. Bell and M. Reich (eds.) Health, Nutrition, and Economic Crises: Approaches to Policy in the Third World, Dover, MA: Auburn House.

Jowett, M., Contoyannis, P. and Vinh, N.D. (2003) 'The impact of public voluntary health insurance on private health expenditures in Vietnam', Social Science \& Medicine 56(2): 333-342.

Kale, R. (1995) 'South Africa's health: Impressions of health in the new South Africa: A period of convalescence', British Medical Journal 310(6987): 1397-1399.

Knaul, F., Arreola-Ornelas, H., Méndez-Carniado, O., Bryson-Cahn, C., Barofsky, J., Maguire, R., Miranda, M. and Sesma, S. (2006) 'Evidence is good for your health system: Policy reform to remedy catastrophic and impoverishing health spending in Mexico', The Lancet 368(9549): 1828-1841. 
Leuven, E. and Sianesi, B. (2003) 'PSMATCH2: Stata module to perform full Mahalanobis and propensity score matching, common support graphing, and covariate imbalance testing', version 3.1.5, 2 May 2009, from http://ideas.repec.org/c/boc/bocode/s432001.html.

Limwattananon, S., Tangcharoensathien, V. and Prakongsai, P. (2007) 'Catastrophic and poverty impacts of health payments: Results from national household surveys in Thailand', Bulletin of the World Health Organization 85(8): 600-606.

Lindelow, M. and Wagstaff, A. (2005) Health shocks in China: Are the poor and uninsured less protected?, World Bank Policy Research Working Paper No. 3740.

McIntyre, D. (2010) 'National health insurance: Providing a vocabulary for public engagement', in A. Padarath and S. Fonn (eds.) South African Health Review, Pretoria: Health Systems Trust.

McIntyre, D. and Ataguba, J.E. (2011) 'How to do (or not to do) ... a benefit incidence analysis', Health Policy and Planning 26(2): 174-182.

McIntyre, D. and Gilson, L. (2002) 'Putting equity in health back onto the social policy agenda: Experience from South Africa', Social Science \& Medicine 54(11): 1637-1656.

McIntyre, D., Doherty, J.E. and Ataguba, J.E. (2012) 'Health care financing and expenditure: Post-1994 progress and remaining challenges', in H.C.J. Van Rensburg (ed.) Health and Health care in South Africa, Pretoria: Van Schaik.

McIntyre, D., Garshong, B., Mtei, G., Meheus, F., Thiede, M., Akazili, J., Ally, M., Aikins, M., Mulligan, J.A. and Goudge, J. (2008) 'Beyond fragmentation and towards universal coverage: Insights from Ghana, South Africa and the United Republic of Tanzania', Bulletin of the World Health Organization 86(11): 871-876.

McIntyre, D., Goudge, J., Harris, B., Nxumalo, N. and Nkosi, M. (2009) 'Prerequisites for National Health Insurance in South Africa: Results of a national household survey', South African Medical Journal 99(10): 725-729.

McIntyre, D., Thiede, M., Nkosi, M., Mutyambizi, V., Castillo-Riquelme, M., Gilson, L., Erasmus, E. and Goudge, J. (2007) A Critical Analysis of the Current South African Health System, Cape Town: Health Economics Unit, University of Cape Town and Centre for Health Policy, University of the Witwatersrand.

McIntyre, D.E. and Doherty, J.E. (2004) 'Health care financing and expenditure: Progress since 1994 and remaining challenges', in H.C.J. Van Rensburg (ed.) Health and Health care in South Africa, Pretoria: Van Schaik.

Mills, A. (2007) 'Strategies to achieve universal coverage: Are there lessons from middle income countries', A commissioned paper: London School of Hygiene and Tropical Medicine, London, from http:// www.who.int/social_determinants/resources/csdh_media/universal_coverage_2007_en.pdf, accessed 5 November 2009.

Nguyen, C.V. (2012) 'The impact of voluntary health insurance on health care utilization and out-of-pocket payments: New evidence for Vietnam', Health Economics 21(8): 946-966.

O'Donnell, O., Van Doorslaer, E., Wagstaff, A. and Lindelow, M. (2008) Analyzing Health Equity Using Household Survey Data: A Guide to Techniques and Their Implementation, Washington, D.C: World Bank Publications.

Rosenbaum, P.R. and Rubin, D.B. (1983a) 'Assessing sensitivity to an unobserved binary covariate in an observational study with binary outcome', Journal of the Royal Statistical Society, Series B 45(2): $212-218$

Rosenbaum, P.R. and Rubin, D.B. (1983b) 'The central role of the propensity score in observational studies for causal effects', Biometrika 70(1): 41-55.

Rosenbaum, P.R. and Rubin, D.B. (1985) 'Constructing a control group using multivariate matched sampling methods that incorporate the propensity score', American Statistician 39(1): 33-38.

Sapelli, C. and Vial, B. (2003) 'Self-selection and moral hazard in Chilean health insurance', Journal of Health Economics 22(3): 459-476.

Sauerborn, R., Nougtara, A., Hien, M. and Diesfeld, H.J. (1996) 'Seasonal variations of household costs of illness in Burkina Faso', Social Science \& Medicine 43(3): 281-290.

Sepehri, A., Sarma, S. and Simpson, W. (2006) 'Does non-profit health insurance reduce financial burden? Evidence from the Vietnam living standards survey panel', Health Economics 15(6): 603-616.

StataCorp (2009) Stata: Release 11-Statistical Software, College Station, TX: StataCorp LP. 
654

Trujillo, A.J., Portillo, J.E. and Vernon, J.A. (2005) 'The impact of subsidized health insurance for the poor: Evaluating the Colombian experience using propensity score matching', International Journal of Health care Finance and Economics 5(3): 211-239.

Wagstaff, A. (2010) 'Estimating health insurance impacts under unobserved heterogeneity: The case of Vietnam's health care fund for the poor', Health Economics 19(2): 189-208.

Wagstaff, A. and Pradhan, M. (2005) Health insurance impacts on health and nonmedical consumption in a developing country, World Bank Policy Research Working Paper 3563.

Wagstaff, A. and van Doorslaer, E. (2003) 'Catastrophe and impoverishment in paying for health care: With applications to Vietnam 1993-98', Health Economics 12(11): 921-933.

Wagstaff, A., Lindelow, M., Jun, G., Ling, X. and Juncheng, Q. (2009) 'Extending health insurance to the rural population: An impact evaluation of China's new cooperative medical scheme', Journal of Health Economics 28(1): 1-19.

Wagstaff, A., Van Doorslaer, E. and Paci, P. (1991) 'On the measurement of horizontal inequity in the delivery of health care', Journal of Health Economics 10(2): 169-205.

Waters, H.R. (1999) 'Measuring the impact of health insurance with a correction for selection bias--A case study of Ecuador', Health Economics 8(5): 473-483.

World Health Organization (2010) The World Health Report 2010: Health Systems Financing: The Path to Universal Coverage, Geneva: World Health Organization.

Yip, W. and Berman, P. (2001) 'Targeted health insurance in a low income country and its impact on access and equity in access: Egypt's school health insurance', Health Economics 10(3): 207-220.

Zweifel, P., Breyer, F. and Kifmann, M. (2009) Health Economics, Heidelberg: Springer-Verlag.

\section{About the Authors}

John Ele-Ojo Ataguba is a Commonwealth scholar and a lecturer at the Health Economics Unit, University of Cape Town, South Africa. He holds a Master's degree specialising in Health Economics from the University of Cape Town, where he is currently completing his $\mathrm{PhD}$ in Economics. Ataguba's major research interests relate to issues of equitable health care and health care financing in Africa. He has research experience in many African countries.

Dr Jane Goudge, the Director of the Centre for Health Policy in South Africa, is a senior researcher in the field of health systems and policy research. Her research has focused on the interaction between households and the health system, particularly the affordability of care and the extent to which the costs cause impoverishment, as well as the reasons as to why patients withdraw from Antiretroviral (ARV) treatment, the role of community caregivers in bridging the gap between households and the health system, and the potential of universal coverage in financing to increase access to care. 